SHORT REPORT

\title{
Quality of Care Research in The Netherlands: the Development and Implementation of Indicators and Instruments
}

\section{R. KLOP* and A. F. CASPARIE $\ddagger$}

*Secretary, Programme Committee for Quality of Care Research, Council for Medical Research of The Netherlands Organization of Scientific Research (NWO), The Hague, The Netherlands

$\ddagger$ Professor, Department of Health Policy and Management, Erasmus University, Rotterdam, The Netherlands

\section{INTRODUCTION}

In The Netherlands, in 1990, agreements were made on a comprehensive and joint national quality of care policy between the organizations of the three parties involved in health care-providers, patients and insurerswith the Government as advisor. To support implementation of this policy, it was realized that scientific research relevant to the methods used in quality management was necessary, especially in areas in which quality management was rather new or needed encouragement. Therefore, at the request of the Dutch Ministry of Welfare, Health and Cultural Affairs, the Council for Medical and Health Research of The Netherlands Organization of Scientific Research designed a programme to stimulate quality of care research in three areas: care for the mentally retarded, home care and care for people with chronic diseases (physical as well as mental). The total available research budget was approximately US\$ 6 million for four years (1992-1995).

\section{GOALS OF THE PROGRAMME}

Scientific research in the field of quality management is fairly new. It is a multi-disciplinary research area in which a research tradition does not exist. An expert committee was therefore established to develop the research programme. The goals of the programme were:

- to develop standards, criteria and instruments to safeguard and enhance quality of care in the areas mentioned;

- to stimulate research activities by funding groups that have potential for this type of research, thus anchoring research lines;

- to create a basis for the application of results by bringing about strong links between research groups and care providers.

\section{RESULTS}

\section{State of the art studies}

To find out what specific quality of care research questions are relevant in the areas concerned, six state-of-the-art studies were funded to investigate:

- outcome indicators for people with chronic diseases;

- outcome indicators for the care of the mentally retarded;

- process indicators for the care of the mentally retarded;

- outcome indicators for the care of people with chronic psychiatric diseases;

- factors facilitating or obstructing the implementation of research results;

- measurement instruments to evaluate discontinuities in care provision.

\section{RESEARCH PROJECTS}

The first round was an open invitation to submit research proposals in order to obtain 
better insight into current activities and interests in the field. The following research proposals were funded:

- chronic disease patients' evaluations of the quality of care provided by general practitioners (GPs);

- quality of home care from the patients' perspective: developing an evaluation instrument;

- the effectiveness and adequacy of care for stroke patients;

- standard analyses and quality control in health care organizations;

- the effect of a training programme for GPs on the detection and management of anxiety and depression in primary care, and on treatment outcomes.

In the second round, research groups were asked to work out research questions on the following subjects that stem from the state of the art studies:

- continuity of care in home care and care for the mentally retarded;

- written care management programs in care for the mentally retarded.

\section{The documentation centre}

A documentation centre was funded for the duration of the programme for 4 years. After this period, two organizations will continue to offer the services of the centre. The centre provides services to researchers by collecting both published and unpublished articles. This data-base is available on floppy-disc.

\section{FUTURE ACTIVITIES}

As a result of the findings of these two rounds, and after meetings with experts in this field, the committee has decided to issue a restricted call to research groups to submit proposals on the implementation and use of instruments for measuring quality of care, on research into factors which promote or hamper implementation of quality improvement, and on identification of high quality care systems. In addition, participating researchers are invited to attend workshops about relevant quality of care research topics, e.g. theoretical concepts of patient satisfaction and outcome indicators in the care of patients with chronic diseases.

\section{CONCLUSIONS}

This comprehensive programme has stimulated quality of care research in the areas of chronic disease, mental retardation and homecare and, in this way, has promoted the development of quality management in these areas. A strong link between research and daily practice has been established. After initially emphasizing research on quality assessment, in its second phase the programme will also stimulate research activities in quality improvement. 